Journal of Computer Science 4 (11): 916-921, 2008

ISSN 1549-3636

(C) 2008 Science Publications

\title{
Web-based Projects Evaluation Management System
}

\author{
${ }^{1}$ Saleem Al-Zoubi, ${ }^{1}$ Zeyad M. Alfawaer and ${ }^{2}$ Mohammad Al-Zoubi \\ ${ }^{1}$ Applied Science University Amman, Jordan, \\ ${ }^{2}$ University Utara Malaysia
}

\begin{abstract}
This project designs a Web-based evaluation management system for the College of Arts and Sciences (CAS). Problem statement: The Msc students in College of Arts and Sciences (CAS) in applied sciences had to take their final project as a project paper in order to fulfill the requirements of their programs and be able to graduate. The final project was evaluated in two parts; first part is representing $40 \%$ of the total mark and evaluated by evaluators. Second part was representing $60 \%$ of the total mark and evaluated by the student's supervisor. These evaluation were done manually. Both the evaluators and supervisors had to fill in the evaluation forms manually and submit them to the office. Approach: The design research methodology or sometimes called "improvement research" contained the major steps: Awareness the problem, suggestion, development, evaluation and conclusion. Results: Both evaluators and supervisors can fill in the evaluation forms through the Internet. Bring the advantage of saving time and resources over traditional paper and pencil scan sheet method. For enhancing the performance of current final project evaluation process in College of Arts and Sciences (CAS) this study proposed a web based evaluation management system to replace the current paper forms used by the evaluators and supervisors. Conclusion: Implementing this system will enable the evaluation results to be entered, presume and retrieved anytime anywhere.
\end{abstract}

Key words: Online management evaluation systems, evaluation management systems, prototype

\section{INTRODUCTION}

Web-based systems are living systems. They rapidly evolve in their functionality, scope, content and use. Reusing previously developed components is an effective way of dealing with this evolution. Web-based systems change and grow rapidly in their requirements, contents and functionality during their life cycle-much more than what we'd normally encounter in traditional software, information and engineering systems. Webbased system development is a continuous activity without specific releases as with conventional software. Thus, a Web-based system is like a garden-it continues to evolve and grow ${ }^{[1]}$.

Online evaluations have the potential to affect professional and academic advancement, promotion and tenure. Few areas in higher education cause more anxiety than course evaluations and few areas have been studied more for validity and reliability ${ }^{[2]}$. At a time when online course methods such as teaching, testing, grading and discussion are commend, online evaluations bring the advantage of saving time and resources over the traditional paper and pencil scan sheet method. Thus, instructors may be encouraged or even required to use them in place of the more cumbersome paper method and results can also be entered online.

Literature review: Online Management evaluation is typically seen in the form of a database of multiplechoice items posted on the Internet with secured access $^{[3]}$. Even though multiple choice items are the typical form of evaluation seen on the Internet, many software programs also have the capability of using fillin-the-blank and essay items and some are even capable of producing evaluation forms that use a variety of multimedia tools ${ }^{[4]}$.

There are concerns with the use of online Management evaluation methods for student evaluation. One concern is the lack of resources; more specifically, the limited hardware, software and technical expertise that may be needed. A second concern lies in the area of security and reliability of the evaluation system. An additional system, or a back-up plan, should be in place in the event of a breakdown of the system. One major benefit of online evaluation is the amount of time that is saved compared to the traditional paper forms ${ }^{[3]}$. Management System Since the paper forms are no longer needed, institutions are able to save money that 
would have been spent on the paper form and the time spent to score the grades.

A lot of researchers have examined faculty teaching evaluations using online surveys ${ }^{[5,6]}$. In a survey of 200 "most wired" schools, 98\% still use paper-based evaluation forms and only $25 \%$ of the faculty receives the course evaluations within 2 weeks of the end of the survey ${ }^{[7]}$. As has been mentioned one challenge of institutions that have changed to web based surveys is the low response rates they get ${ }^{[7]}$. In addition some students have expressed concerns about the privacy of the data gathered. However ${ }^{[8]}$, argues that if completion of web-based surveys is strongly encouraged by administrators and faculty, web-based evaluations can achieve response comparable to traditional methods. As regards web surveys in general $^{[9]}$, argues that the inclusion of HTML tables, animation, sound tracks, java applets and other advanced features, (which some see as a means of getting respondents to provide answers) may have the effect of making the questionnaire difficult for some respondents to access or complete.

Previous research indicates both benefits and limitations inherent in online evaluations. The benefits include time and cost savings, faster reporting of results and possible improved quantity and quality of student comments ${ }^{[10]}$. In addition, online evaluations are less subject to faculty influence, allow students to take as much time as they wish to complete the evaluation and also allow students to choose the time they wish to complete the evaluation ${ }^{[11]}$.

One study reported that students preferred completing electronic instructor evaluations to paper ones $^{[12]}$. A focus group in another study reported that the online tool was easy to use, students liked the anonymity of the online evaluation and the online evaluation allowed them to offer more thoughtful remarks than did the traditional, inclass, print-based teaching evaluation ${ }^{[13]}$. In another study, over $90 \%$ of students marked Agree or Strongly Agree when asked if they preferred online to traditional evaluation format ${ }^{[11]}$.

Some research found those faculties prefer traditional evaluations because they believe traditional methods produce a higher rate of return and more accurate responses ${ }^{[14]}$. Some faculties who are not proficient with computers or knowledgeable about online surveys also believe that online evaluations are less accurate than traditional ones ${ }^{[11]}$. Other concerns voiced by faculty who object to online evaluations include the beliefs that quantitative scores are lower, negative comments are more frequent, student return rate is lower and while students voice more dissatisfaction with less favored instructors, they are not as motivated to express satisfaction with more favored instructors $^{[13]}$.

UUM has developed an on-line system to allow lechers to enter students PG and UG marks to rename it after the marking exams; this system has made it more easy and efficient for the transmission of results.

Problem statement: The MSc students in College of Arts and Sciences (CAS) in Applied Sciences have to take their final project as a project paper in order to fulfill the requirements of their programmes and be able to graduate. This final project is evaluated in two parts; the first part is representing $40 \%$ of the total mark. This part is evaluated by evaluators. The second part is representing $60 \%$ of the total mark and is evaluated by the student's supervisor.

At present all above mentioned evaluation are done manually. Thus both the evaluators and supervisors have to fill in the evaluation forms and submit them to the office. It takes time to fill the forms and to get all the marks together.

Thus this study proposes the web-based MSc project evaluation management system where both evaluators and supervisors can fill in the evaluation forms through the Internet. The main objective of this study is to design and develop a web based MSc project evaluation management system to replace the current paper forms used by the evaluators and supervisors in College of Art and Sciences in UUM in order to enhance the assessment process.

The sub-objectives are to identify the requirements and design the system. Designing and implementing this proposed system successfully will benefit many parties; firstly the evaluators can access the evaluation forms anytime, the forms can be taken and filled anywhere and the evaluation process be done using a simple personal computer and the minimal requirement is just a Web browser. The second parties are the administration where the marks are automatically collected, analyzed and submitted.

\section{MATERIALS AND METHODS}

According to ${ }^{[15]}$, the design research methodology or sometimes called "Improvement Research" contained the major steps: Awareness the Problem, Suggestion, Development, Evaluation and conclusion as shown in Fig. 1.

Awareness of problem gives the picture of the problem and some ideas of the problem solving. The Suggestion phase follows after the Awareness of Problem phase and is closely connected with it; the output of the Suggestion phase is Tentative Design. 
J. Computer Sci., 4 (11): 916-921, 2008

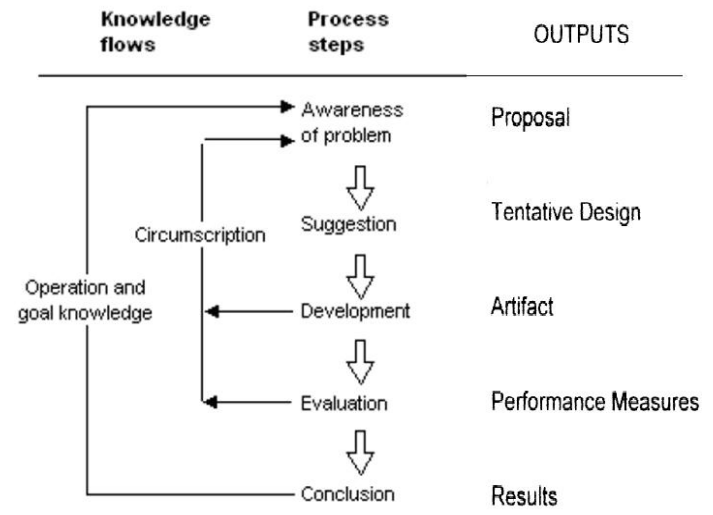

Fig. 1: General methodology of design research ${ }^{[16]}$

The Development phase is the implementation of the Tentative Design. The implementation techniques will be different depending on the artifact to be created. In the Evaluation phase, the artifact is evaluated following the standards, which will be understood and clear in the Proposal. The results from evaluation is indicated the consideration of future work and used as feedback to another round of the Suggestion phase. The Conclusion phase is the last part of the design research methodology.

Data collection is important in producing a requirement model and prototype that really satisfied consumers' needs. For this reason, a qualitative interview and document sampling study are conducted with the CAS staff that involved in MSc project evaluation management. Five staff members were selected as interviewee to gather current information about the initial process until the complete processes that are needed in MSc project evaluation. After getting this information, a structured interview with the person's in-charge of CAS has been conducted. The preliminary interviews is that the researcher can adapt the questions as necessary, clarify doubts and ensure that the responses and properly understood, by repeating or rephrasing the questions. Firstly, the purposes of the interview were defined and some research questions were formulated. After that, the right interviewees were identified for the interview. The five interviewees were selected due to involve critically in management of project evaluation process. This process was implemented through face to face interview and preprepared questionnaire. In order to make the interviews more structured, a requirements survey was prepared for the respondents and to make it easier for them to provide the information we need in this research.
Table 1: Functional requirements

\begin{tabular}{|c|c|}
\hline Requirement & Description \\
\hline Requirement 1 & $\begin{array}{l}\text { The system should allow the lecturer to EDIT his } \\
\text { own students details }\end{array}$ \\
\hline Requirement 2 & $\begin{array}{l}\text { The system should allow the lecturer FILL the } \\
\text { evaluation form for his own students }\end{array}$ \\
\hline Requirement 3 & $\begin{array}{l}\text { The system should allow the lecturer to ADD new } \\
\text { student to his own list of students }\end{array}$ \\
\hline Requirement 4 & $\begin{array}{l}\text { The system should allow the lecturer to FILL the } \\
\text { proposal evaluation form for other students not } \\
\text { supervised by him }\end{array}$ \\
\hline Requirement 5 & $\begin{array}{l}\text { The system should allow the lecturer to FILL the } \\
\text { findings evaluation form for other students not } \\
\text { supervised by him }\end{array}$ \\
\hline Requirement 6 & $\begin{array}{l}\text { The system should allow the lecturer to FILL the } \\
\text { report evaluation form for other students not } \\
\text { supervised by him }\end{array}$ \\
\hline Requirement 7 & $\begin{array}{l}\text { The system should allow the student to his } \\
\text { proposal evaluation result }\end{array}$ \\
\hline Requirement 8 & $\begin{array}{l}\text { The system should allow the student to his findings } \\
\text { evaluation result }\end{array}$ \\
\hline Requirement 9 & $\begin{array}{l}\text { The system should allow the student to his Report } \\
\text { evaluation result }\end{array}$ \\
\hline
\end{tabular}

The respondents' answers to the survey were as follow:

- All respondents agreed on that a web-based evaluation system will help CAS in enhancing the performance of the current evaluation process followed by CAS

- All respondents advised to follow the current process as it is with no modifications on the process itself and to use the current paper-based forms used in evaluation exactly

- Some of the respondent suggested the use of usability testing in order to test the system's functionality and performance

Information from the interview was arranged and readapt properly. This information is recorded in question and answer format so that data collection can be managed easily.

System requirements: Based on the objectives and the definition of the Use Cases, the description of the requirements for this system explained in Table 1. The requirements for this system are organized according to different aspects of the system ${ }^{[16]}$ that is, system performance and functionality.

\section{RESULTS AND DISCUSSION}

System design and system architecture: Microsoft Visio is used to draw necessary diagrams that help in the development stage. Use case diagram, as displayed in Fig. 2 describes the overall interaction between the system and its users. 
Evaluate other students use case begins when the Lecturer select to evaluate other students. The system displays a list of students and the Lecturer chooses one student, additionally the Lecturer Chooses the type of evaluation he wishes to perform (A1, A2 and A3). The system display a form for evaluation to let the lecturer fills this form. Finally the system records the lecturer evaluation:

A1: The lecturer chooses to evaluate Proposal; the system will display the proposal evaluation form

A2: The lecturer chooses to evaluate Findings; the system will display the Findings evaluation form

A3: The lecturer chooses to evaluate Report; the system will display the proposal evaluation form

As illustrated in the previous sequence diagram Fig. 3 both the student and the lecturer have to login to the system and verify their roles, also Fig. 4 shows the steps done by each user to interact with the system in order to reach the desired function.

System architecture: For the system architecture, the three-tier architecture model is the best structure for our system. Here is how the three-tier model is incorporated into the system as shown in Fig. 5:

Tier 1: The client side of the architecture. The user will be shown formatted HTML pages resulting from ASP.net code, which will be submitted to the application middleware for processing. It will actually be the front-end of the system and it is where the user will interact with the system

Tier 2: The middleware side or the application tier. Main applications used in this layer are .NET Framework, which will be processed by a web server, i.e., Microsoft IIS Also in this tier will be the SSL protocol if it is exist, to make sure the system and data is secure from unauthorized users

Tier 3: The backend side of the architecture and where all the data and records are kept. Also known as the business data, the technology used store the business data is Microsoft SQL Sever 2005

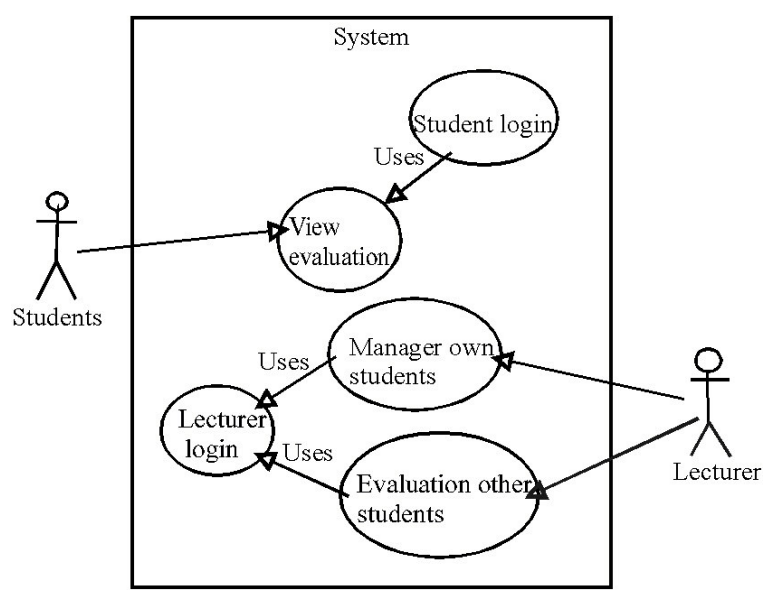

Fig. 2: Use case diagram

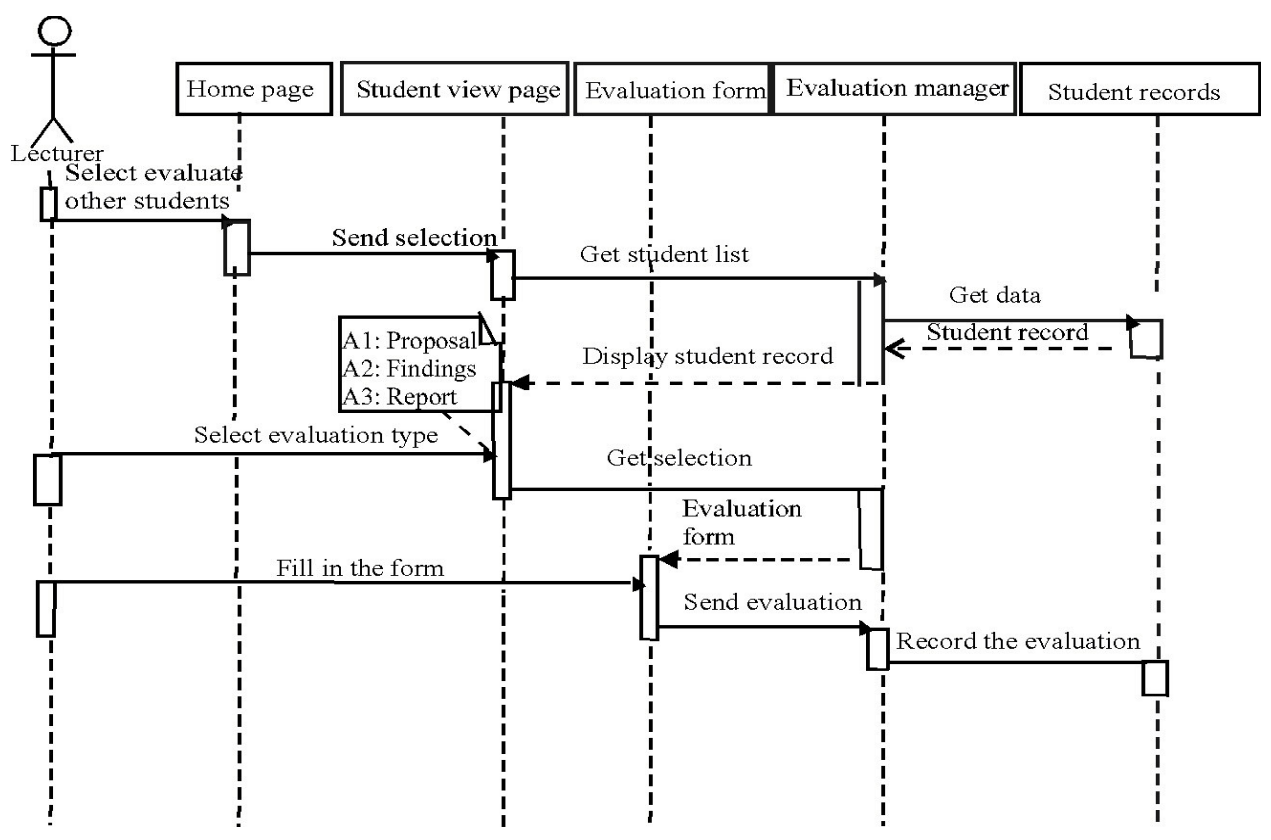

Fig. 3: Evaluate students sequence diagram 


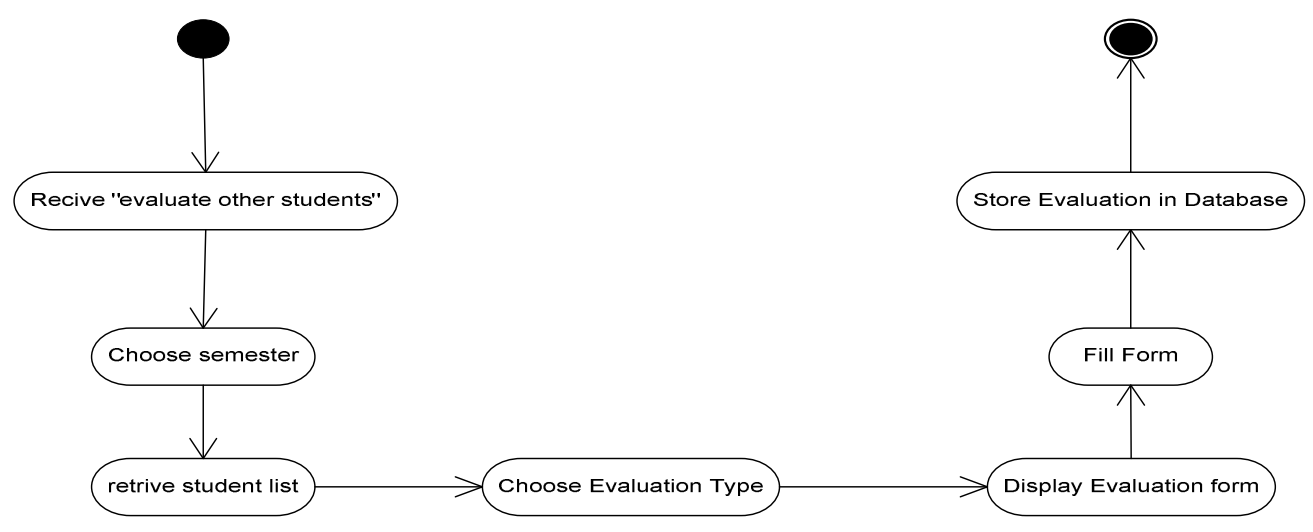

Fig. 4: Evaluate students activity diagram

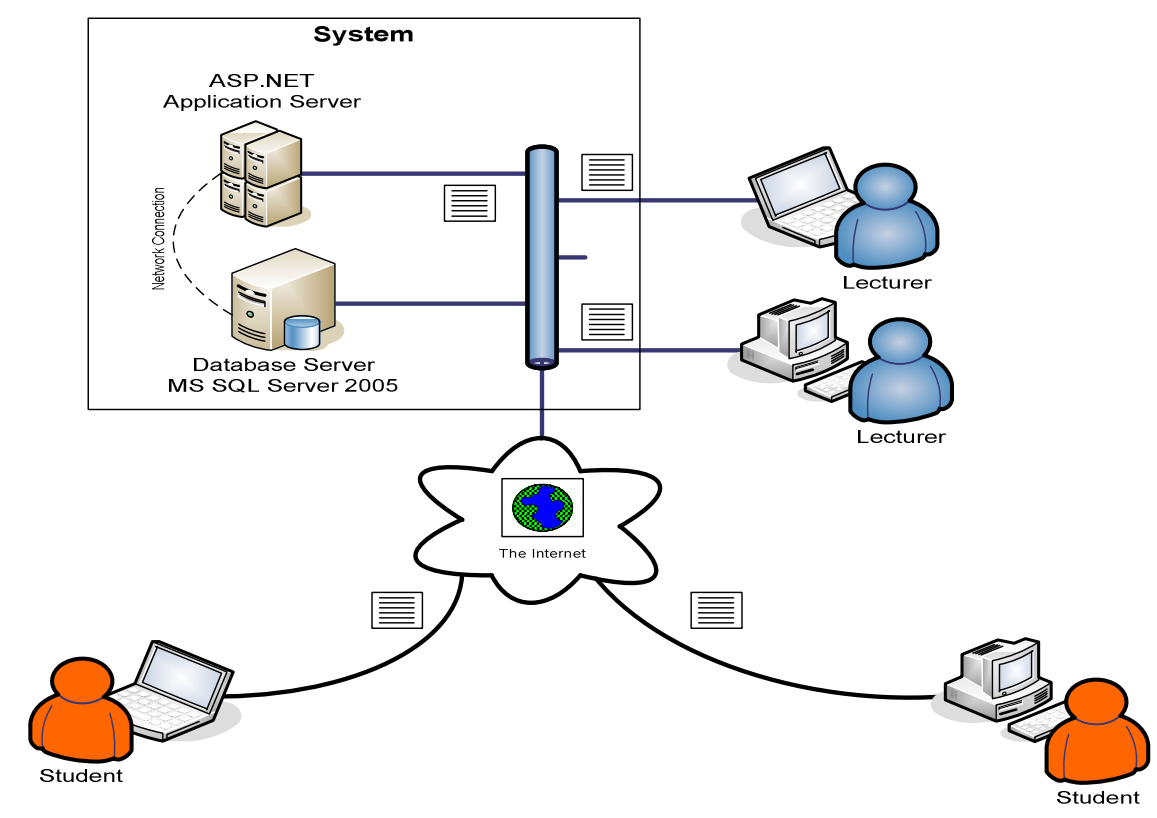

Fig. 5: System architecture

\section{CONCLUSION}

A web-based project evaluation system was developed for CAS in order to enhance the projects evaluation process performance and increase the CAS staff productivity. In addition this web-based evaluation system can promote the academicians of CAS convenience by offering them a web option for performing their evaluation tasks which can be available anywhere anytime.

Implementing this system will return in many benefit for both CAS academicians and managerial staff at the same time. The CAS staff can save time and effort and keep informed of the students' projects details anywhere anytime. In addition the students can access the system and view their projects evaluation details like corrections and recommendations and grading.

Some work and further studies still need to be conducted for this system in order to make it more functional and reliable such as expanding and generalizing the system to include all CAS postgraduate programs and fully integrating the system database as mentioned in the recommendations section.

Recommendations and future research: Regarding this study prototype, one important consideration for future development and projects is to conduct a detailed 
study on the best way for integrating the databases of all related departments in UUM like postgraduate school registration office. This integration must ensure the reliability of this prototype database and must guarantee the consistency of the data stored and retrieved from this database. A possible way to achieve this goal is to build a data warehouse for the whole departments databases related and linking this system to the data warehouse instead of linking it to a stand alone database.

\section{ACKNOWLEDGEMENT}

This work was supported by Applied Science University.

\section{REFERENCES}

1. Powell, T.A., 1998. Web Site Engineering: Beyond Web Page Design. 1st Edn., Prentice Hall, Upper Saddle River, NJ., ISBN: 0136509207, pp: 324.

2. Wachtel, H.K., 1998. Student evaluation of college teaching effectiveness: A brief review. Assess. Evaluat. Higher Educ., 23: 191-211. DOI: 10.1080/0260293980230207

3. Bocij, P. and A. Greasley, 1999. Can computerbased testing achieve quality and efficiency in assessment? Int. J. Educ. Technol., 1: 1-18. http://www.ascilite.org.au/ajet/ijet/v1n1/bocij/

4. Chauncey, H., 1995. A calm before the storm? Yale Alumni. Mag., 58: 30-31.

5. Dommeyer, C., P. Baum, R. Hanna and K. Chapman, 2004. Gathering faculty teaching evaluations by inclass and online surveys: Their effects on response rates and evaluations. Assess. Evaluat. Higher Educ., 29 : 611-623. 10.1080/02602930410001689171

6. Hmieleski, K. and M.V. Champagne, 2000. Plugging in to course evaluations. The technology source.

http://technologysource.org/article/plugging_in_to_ course_evaluation/

7. Hmieleski, K., 2000. Barriers to online evaluation: Surveying the nation's top 200 most wired colleges. Report prepared by Interactive and Distance Education Assessment (IDEA) Laboratory, Rensselaer Polytechnic Institute, Troy, NY.
8. McGourty, J., K. Scoles and S. Thorpe, 2002. Web-based course evaluation: Comparing the experience at two universities. Proceeding of the 32nd ASEE/IEEE Frontiers in Education Conference, March 21-21, Boston, MA., http://fie.engrng.pitt.edu/fie2002/papers/1328.pdf

9. Dillman, D., R.L. Tortora, J. Conradt and D. Bowker, 1998. Influence of Plain vs. fancy design on response rates for web surveys. http://survey.sesrc.wsu.edu/dillman/papers/asa98pp r.pdf

10. Kuhtman, M., 2004. Review of online student ratings of instruction. College Univ. J., 80: 64-67.

11. Anderson, H.M., J. Cain and E. Bird, 2005. Online course evaluations: Review of literature and a pilot study. Am. J. Pharmaceut. Educ., 69: 34-43. http://www.ajpe.org/view.asp?art=aj690105\&pdf=yes

12. Layne, B., J. DeCristoforo and D. McGinty, 1999. Electronic versus traditional student ratings of instructions. Res. Higher Educ., 40: 221-232. http://www.springerlink.com/content/k547563nl86 28671/

13. Ravelli, B., 2000. Anonymous online teaching assessments: Preliminary findings. Proceeding of the Annual National Conference on American Association for Higher Education, June 14-18, Charlotte, North Carolina, pp: 12. http://eric.ed.gov/ERICWebPortal/custom/portlets/ recordDetails/detailmini.jsp?_nfpb=true\&_\&ERIC ExtSearch_SearchValue_0=ED445069\&ERICExtS earch_SearchType_0=no\&accno=ED445069

14. Dommeyer, C., P. Baum, K. Chapman and R. Hanna, 2002. Attitudes of business faculty toward two methods of collecting teacher evaluations: Paper vs. Online. Assess. Evaluat. Higher Educ., 27: 455-462. http://www.ingentaconnect.com/content/routledg/c aeh/2002/00000027/00000005/art00005

15. Vaishnavi, V. and B. Kuechler, 2006. Design Research in information system. http://www.citeulike.org/user/Repton/article/2517447

16. Dong, L., 1998. Modeling top management influence on ES implementation. Bus. Process Manage. J., 7: 243-250. DOI: $10.1108 / 14637150110392737$ 